\title{
Research on the Reuse of Exhaust Energy Based on the Planetary Gears
}

\author{
Aimin $\mathrm{Du}^{1, \mathrm{a}^{*}}$, Changhui Shao ${ }^{2, \mathrm{~b}}$, Yun $\mathrm{Liu}^{3, \mathrm{c}}$ \\ ${ }^{1,2,3}$ School of Automotive Studies, Tongji University, Shanghai 201804, China; \\ a*duaimin1971@aliyun.com, ${ }^{b}$ shaoch77@163.com, ${ }^{\mathrm{c}}$ liuyun12345679@163.com
}

Keywords: Engine; Energy Reused; Turbocharger; Planetary Gear Mechanism;

Abstract. Use of turbocharger can make the energy taken by the exhaust gas be recycled again. A new further innovation of electronic aids turbocharger is made: The turbine and compressor in exhaust gas turbocharger are connected on a planetary gear mechanism with a motor. It is a new solution that the turbine, compressor and motor are connected to each other through the planetary gear mechanism. This program is to make sure the speed of turbine under different working conditions in engine, and then make the speed of compressor always stay at corresponding high-efficiency value through real-time adjustment of the motor speed. Models of all the six schemes are made and simulated by use of the Matlab Simulink software under appropriate simplifying conditions. It is shown that the scheme one is best: compressor and turbine are connected respectively to sun gear and gear ring, while the motor is connected to planet carrier as an output.

\section{Introduction}

Research shows that $1 / 3$ of heat from fuel combustion in the engine dissipate into the atmosphere through the exhaust systems, resulting in a waste of energy and environment pollution ${ }^{[1]}$. Exhaust gas energy recovery is one of the most effective ways of improving the utilization of energy and achieving energy saving and emission reduction ${ }^{[2]}$. However, the conditions of vehicle engine are complex with non-steady-state characteristics, which leads to the transient volatility of exhaust state parameters such as pressure, temperature, flow velocity and mass flow rate ${ }^{[3]}$. As the medium of energy transfer, exhaust gas, of which the state parameters vary with the conditions of engine, make the exhaust energy of various forms fluctuate transiently, and thus energy recovery process is relatively complex. Nevertheless, due to that engine exhaust energy has great potential for recycling; the research of the exhaust gas energy recycling and utilization is of great significance for improving energy efficiency, reducing pollution and improving engine performance.

Turbocharger technology is an important means to improve the use of exhaust gas energy. Modern internal combustion engines are designed for the purpose of high dynamic performance and fuel economy as well as low emissions ${ }^{[4]}$. There is no doubt that turbo boosts engine power and fuel economy, But due to poor transient response characteristics of traditional supercharger, the engine often belching black smoke ${ }^{[5]}$. This situation is clearly incompatible with reducing engine emissions which is initially intended for. Therefore, auxiliary electric supercharge system comes into being. Auxiliary electric supercharge system is designed by integrating the motor and exhaust gas turbine supercharger, which are mounted on one shaft. Compared to ordinary turbocharger, assisted turbocharging system adds the motor, electronic control unit, battery, as well as a variety of sensors ${ }^{[5,6]}$. In this system, motor can drive the turbocharger; can also be used as generators and play a role in the recover of excess energy.

On the basis of existing electric auxiliary booster, this paper proposes an innovative form of auxiliary electric supercharger which is planetary gear-driven auxiliary electric supercharger. Planetary gear mechanism consists o external ring gear, Sun gear, planetary gears and planet carrier composition. Now we conceive an idea of breaking the coaxial connection of turbine and compressor in the conventional layout, Instead make them connect with the outer ring gear and Sun gear of the planetary gear set respectively. Then the motor is connected to the planet carrier by a speed change mechanism. In this layout, the speed of the compressor can be controlled by adjusting the motor speed. In this plan, firstly, solve the corresponding needed air flows according to the different working conditions of the 
engine, then combine with the pressure ratio and flow characteristics of the compressor and general characteristic curve of the turbine, therefore the speeds of the turbine under different working conditions of engine and the corresponding efficient speeds of compressor can be obtained. Thus the compressor can be kept working at efficient speeds throughout by adjusting the motor speed.

\section{Establish the Model Parameters}

Solution for Air Mass Flow Required. There are two ways for the determination of air flow rate, one is from power of the engine, the other one is the engine structure size calculation ${ }^{[2]}$. Both two methods can obtain the air mass flow rate required under different conditions. Base on the actual engine working volume, the amount of air compressor shall provided is as what Eq. 1shows:

$$
\mathrm{G}_{\mathrm{K}}=\frac{\left[\mathrm{ZV} \mathrm{h}_{\mathrm{h}} \mathrm{n} \rho_{\mathrm{K}} n_{\mathrm{V}} \varphi_{\mathrm{K}}\right.}{60}
$$

Among the Eq. 1, i: Amount of cylinders

$\mathrm{Z}$ : Amount of strokes

$\mathrm{V}_{\mathrm{h}}$ : Work capacity of single cylinder, $\mathrm{m}^{3}$

$\mathrm{n}$ :Speed of the engine, $\mathrm{r} / \mathrm{min}$

$\rho_{\mathrm{K}}$ : Pressurized air density, $\mathrm{Kg} / \mathrm{m}^{3}$

$\eta_{v}$ : volumetric efficiency

Solution for Exhaust Mass Flow. According to the law of conservation of mass, the exhaust mass flow can be solved as Eq. 2:

$$
\mathrm{g}_{\mathrm{T}}=\mathrm{G}_{\mathrm{KE}}+\frac{\mathrm{g}_{\mathrm{g}} \mathrm{P}_{\mathrm{e}}}{3600}-\mathrm{G}_{\mathrm{z}}
$$

Among the Eq. 2, $\mathbf{g}_{\mathrm{T}}$ : Exhaust mass flow, $\mathrm{Kg} / \mathrm{s}$

$\mathrm{G}_{\mathrm{K}}$ : Outlet flow of Compressor, $\mathrm{Kg} / \mathrm{s}$

$\mathrm{g}_{\mathrm{e}}$ : Specific fuel consumption, $\mathrm{Kg} /(\mathrm{kW} \cdot \mathrm{h})$

$P_{a}$ : Engine power, $\mathrm{kW}$

$\mathbf{G}_{\mathbf{z}}$ : Leak amount from the exhaust pipe to the turbines import and the gas channeling through crankcase piston ring

Determination of the Exhaust Temperature. It is solved by using the energy conservation in cylinder method. According to the law of conservation of energy, take the cylinder for an isolated system. Sum of the quantity of heat sprayed into the cylinder with fuel and the heat into with the air is same with the amount of the sum of Indicated work heat Equivalent Weight, heat passed to the cooling thing and the heat taken away by waste gas ${ }^{[3,4]}$. It is as the Eq. 3:

$$
\mathrm{T}_{\mathrm{r}}=\frac{\left(1-\mathrm{q}_{\mathrm{E}}\right) \mathrm{H}_{\mu}+\alpha \varphi_{\mathrm{k}} \mathrm{L}_{\mathrm{o}} \mathrm{T}_{\mathrm{k}} \mathrm{C}_{\mathrm{pmk}}-\eta_{\mathrm{i}} \mathrm{H}_{\mu}}{\left(\alpha \varphi_{\mathrm{k}} \mathrm{L}_{\mathrm{o}}+1\right) \mathrm{C}_{\mathrm{pmT}}} .
$$

Among the Eq. 3, $\mathrm{q}_{\mathrm{B}}$ : Heat loss coefficient to the cooling medium

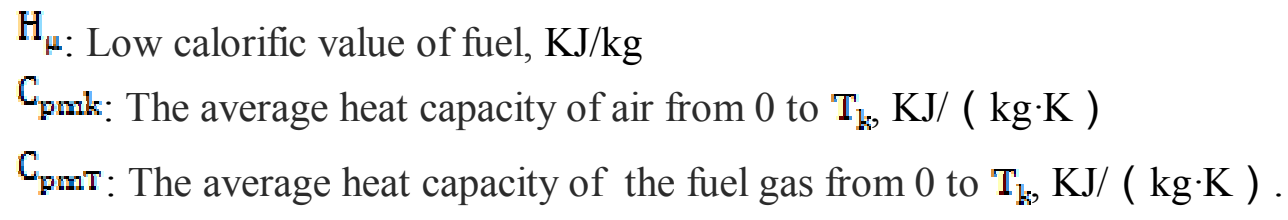

Solution of the Highest Compressor Speed and the Turbine Speed. According to the general characteristic of the compressor, through the atmospheric pressure and the ambient temperature measurement, some parameters under the working condition are made sure,such as the fuel consumption rate, power, excess air coefficient, scavenging coefficient. Then the inlet mass flow rate and the reduced flow rate under the condition can be calculated. The last is to make sure the high speed of compressor according to the general characteristic of the compressor ${ }^{[3,6]}$.

Similarly, we can determine the engine turbine speed under different working conditions. First, determine the exhaust temperature, pressure and mass flow rate, and then calculate the expansion ratio 
and reduced flow, and finally check the reduced speed and actual speed of turbine from the universal characteristic curve of the turbine.

Determination of Planet Gear Mechanism Parameters. The turbine, compressor, and motor should be connected by planet gear mechanism. So it is an important work to determine the planetary gear parameters. It is the typical structure of planetary gear mechanism showed in Fig. 1.

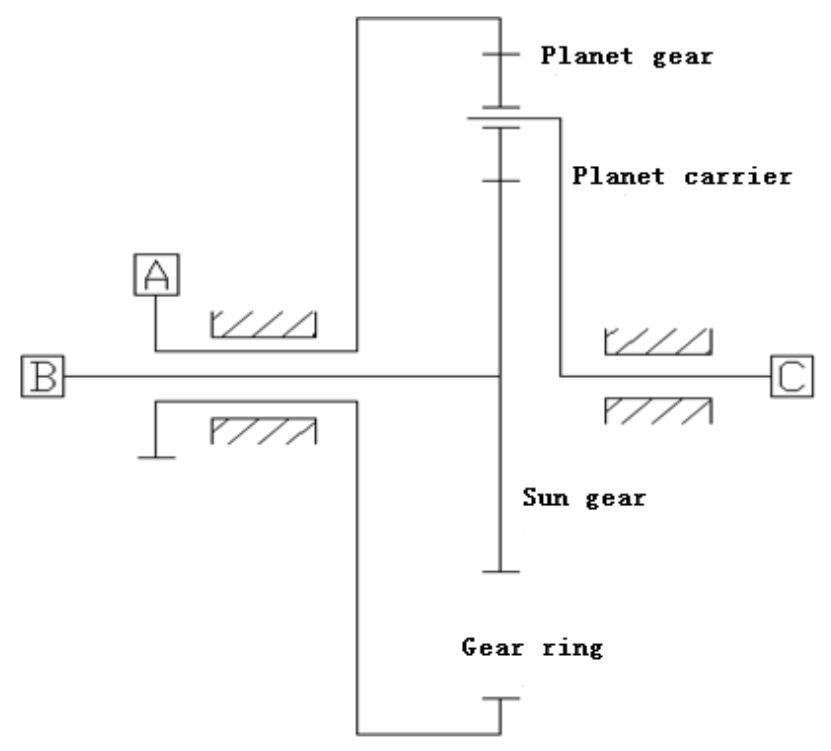

Fig. 1 The typical structure of planetary gear mechanism

Because the amount of each wheel teeth in the planetary gear train should match the transmission ratio, and the mechanism has to be satisfied the concentric condition, uniform and adjacency condition, etc. The amount of sun wheel teeth is determined as 17, and the gear ring is 170 under comprehensive consideration. The relationship among the speeds is as showed in Eq. 4:

$$
\frac{\mathrm{n}_{\mathrm{H}}\left(\mathrm{Z}_{1}+\mathrm{Z}_{\mathrm{Z}}\right)-\mathrm{n}_{\mathrm{g}} \mathrm{Z}_{\mathrm{a}}}{\mathrm{Z}_{1}}=\mathrm{n}_{1}
$$

Among them, $n_{1}, n_{3}, n_{M}$ are respectively the speed of sun wheel, gear ring, and the planet carrier. The compressor is connected to sun wheel and the motor is connected into planet carrier. When the highest speed of compressor under the working condition and the speed of turbine it corresponds are solved, the speed of the motor can be sure according to Eq. 4, and then the compressor can work at the highest speed. As a result, the efficiency of energy use is improved.

\section{The Establishment and Simulation of Model}

Establish the Model. In order to test and verify the feasibility of the new design, the model is properly simplified Because the constraint and the engine exhaust temperature, exhaust pressure can not be sure. In fact, both the speed of turbine and compressor efficiency work speed change along with working conditions of engine. Compressor efficient working speed is artificially simplified to be fixed at 40000rpm now, the turbine speed is constantly changing and no regular generated by function models from Sources module library in Simulink. At last, the speed of compressor can stay in the hypothetical value of 40000rpm when the speed of turbine changes through the real-time adjustment for motor speed. Due to the turbine, compressor and motor can be connection in different parts, according to Fig.1, there are six kinds of schemes just as showed in Table 1. 
Table 1 Schemes of model

\begin{tabular}{|l|l|l|l|}
\hline & A & B & C \\
\hline scheme 1 & turbine & compressor & motor \\
\hline scheme 2 & turbine & motor & compressor \\
\hline scheme 3 & motor & compressor & turbine \\
\hline scheme 4 & compressor & turbine & motor \\
\hline scheme 5 & motor & turbine & compressor \\
\hline scheme 6 & compressor & motor & turbine \\
\hline
\end{tabular}

In scheme 1, for example, model is made and shown in Fig.2.

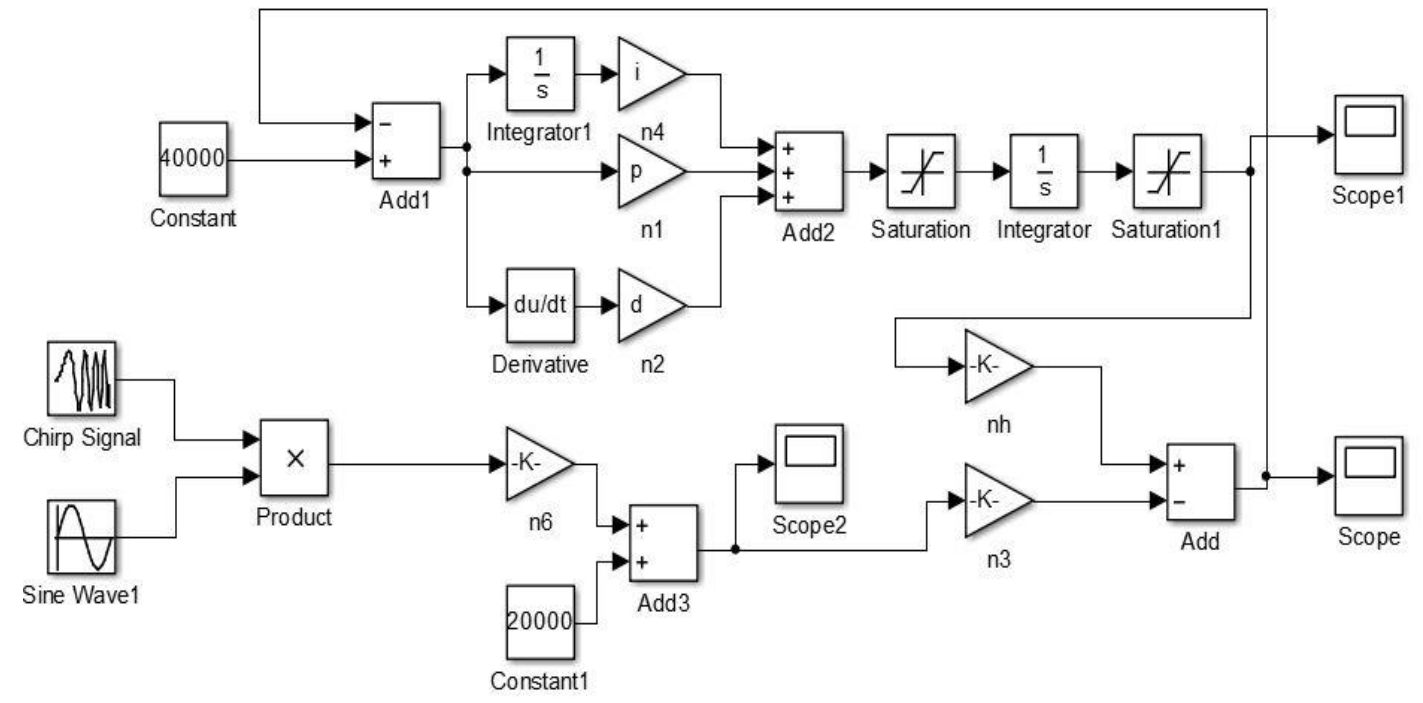

Fig. 2 Model

A no regular waveform changing over time can be got through Linear frequency modulation Signal module (Chirp Signal) multiplied by Sine Signal module (Sine Wave). Just as shown in Fig.3. With the waveform as the turbine speed, speed value changes in the range of $17000 \mathrm{rpm}$ to $25000 \mathrm{rpm}$.

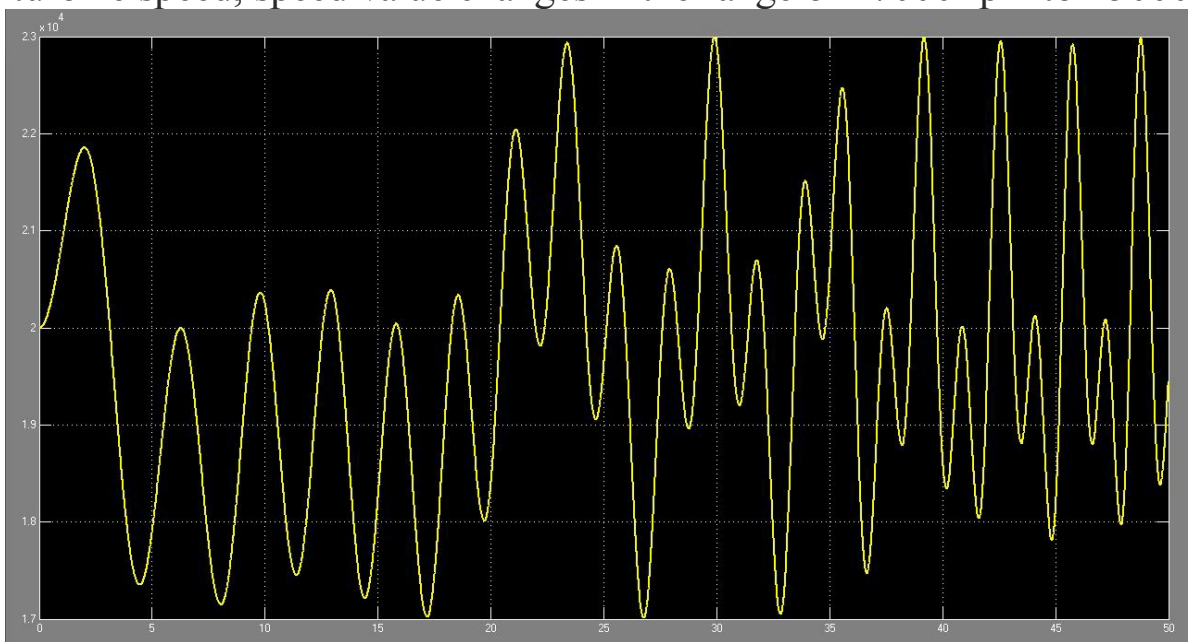

Fig.3 Speed of turbine

Because the model need to real-time monitor the compressor speed and compare it to the target value of 40000rpm, and then adjust the motor speed in order to make the compressor speed stay at 
40000rpm, so PID control link is also important. Define the parameters of PID as: $\mathrm{P}=6, \mathrm{I}=5$, $\mathrm{D}=0.001$.

Due to the speed of the motor need to be adjusted in real time to make the speed of the compressor keep at 40000 RPM as far as possible, but in fact, the change of motor speed needs a process, can't unlimited, so The speed limit module both Saturation and Saturatuon1are used to limit the maximum values of change about accelerated speed and speed in motor per minute.

Simulate and Analyze Model. What Scopel shows is the speed of motor. According to Eq. 4, speed of motor $n_{H}$ multiplied by constant $\left(Z_{1}+Z_{2}\right) / z_{1}$, then minus the value generated by turbine speed $\mathrm{n}_{\mathrm{g}}$ multiplied by constant $\mathrm{Z}_{\mathrm{z}} / \mathrm{Z}_{1}$, as a result, the compressor speed and motor speed can be get shown as Fig.4 and Fig.5.

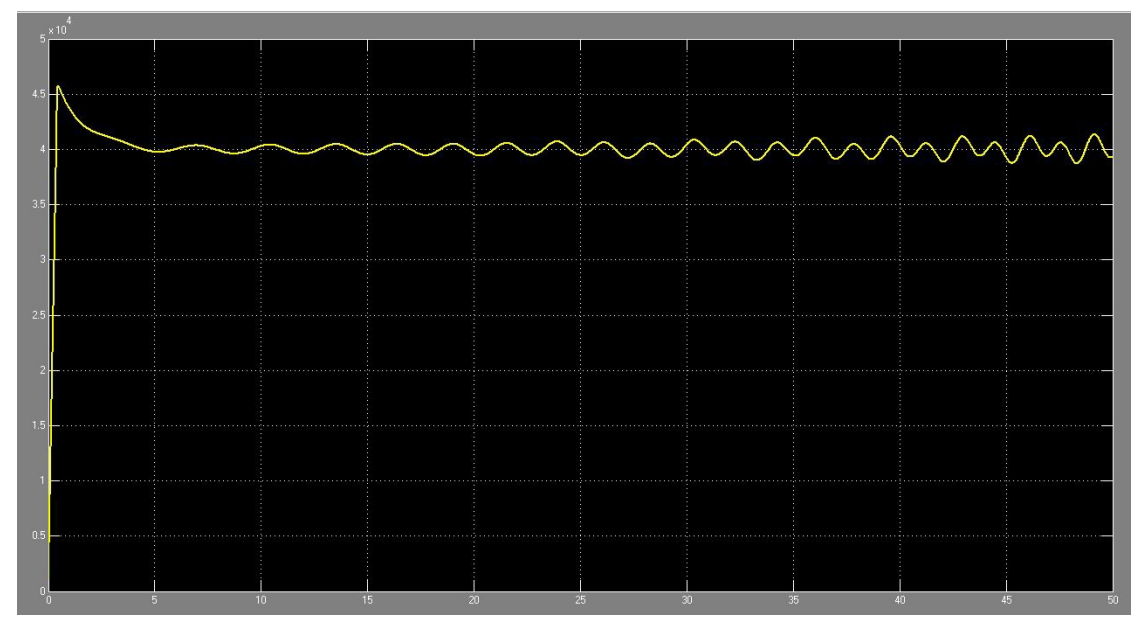

Fig.4 Speed of compressor in scheme 1

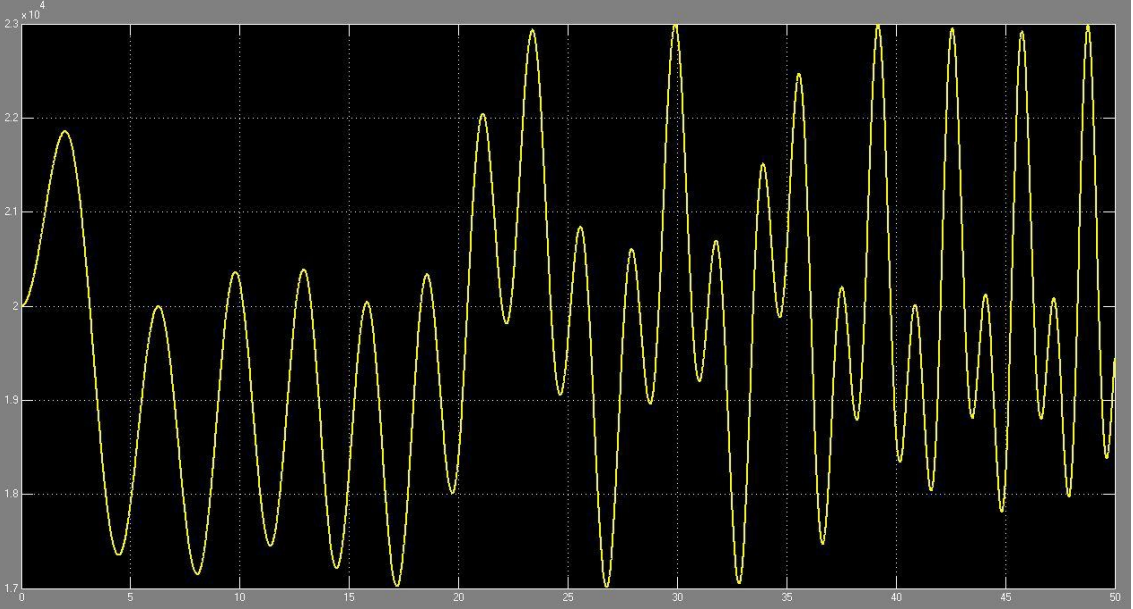

Fig. 5 Speed of motor in scheme 1

It can be seen that compressor speed gradually retreates to the expected value $40000 \mathrm{rpm}$ after a short (5 s) overshoot, and finally stays in 40000rpm with oscillation of small amplitude, the control result is ideal. Although the compressor speed can't fully be controled at 40000rpm after the modules of limitation for motor acceleration and speed are joined, the result is more in line with the actual results because it only shocks slightly around $40000 \mathrm{rpm}$. Motor speed is basic within the $23000 \mathrm{RPM}$, which is normal.

Similarly, the simulations of other schemes can be made. In scheme 2, the coefficient motor speed multiplied by is $Z_{1 /\left(Z_{1}+Z_{B}\right)}$, the number turbine speed multiplied by is $Z_{2} /\left(Z_{1}+Z_{B}\right)$. The result is shown in Fig.6. 


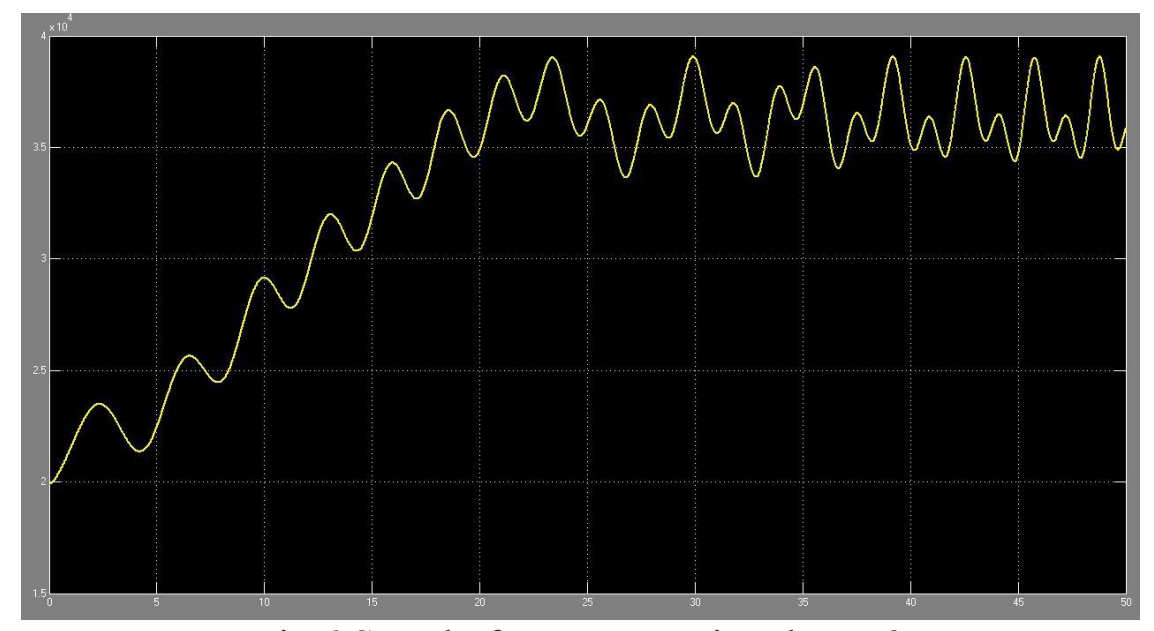

Fig. 6 Speed of compressor in scheme 2

It can be seen that the speed of compressor is always lower than the efficient speed and have large fluctuation (last stabilized in range from 35000rpm to 40000rpm). Besides, it take a long time 20s for compressor to achieve steady speed.

In scheme 3 , the coefficient motor speed multiplied by is $-Z_{3} / z_{1}$, the number turbine speed multiplied by is $\left(Z_{1}+Z_{2}\right) / Z_{1}$. The result is shown in Fig.7.

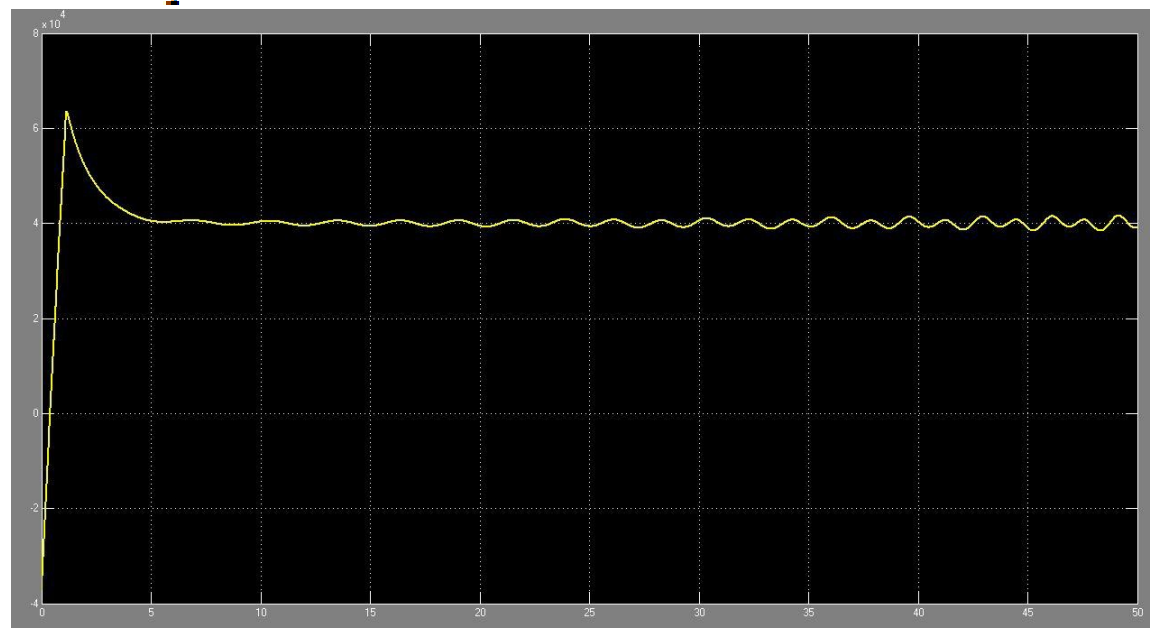

Fig.7 Speed of compressor in scheme 3

It can be seen that the compressor speed finally reaches at $40000 \mathrm{rpm}$, with small amplitudes up and down. But the overshoot is up to 60000rpm which is fifty percent compared to 40000rpm before it achieves the stable status. So the overshoot is very large.

In scheme 4 , the coefficient motor speed multiplied by is $\left(\mathrm{Z}_{1}+\mathrm{Z}_{3}\right)_{2} / \mathrm{Z}_{3}$, the number turbine speed multiplied by is $-Z_{1 / z_{3}}$. The result is shown in Fig.8 and Fig.9. 


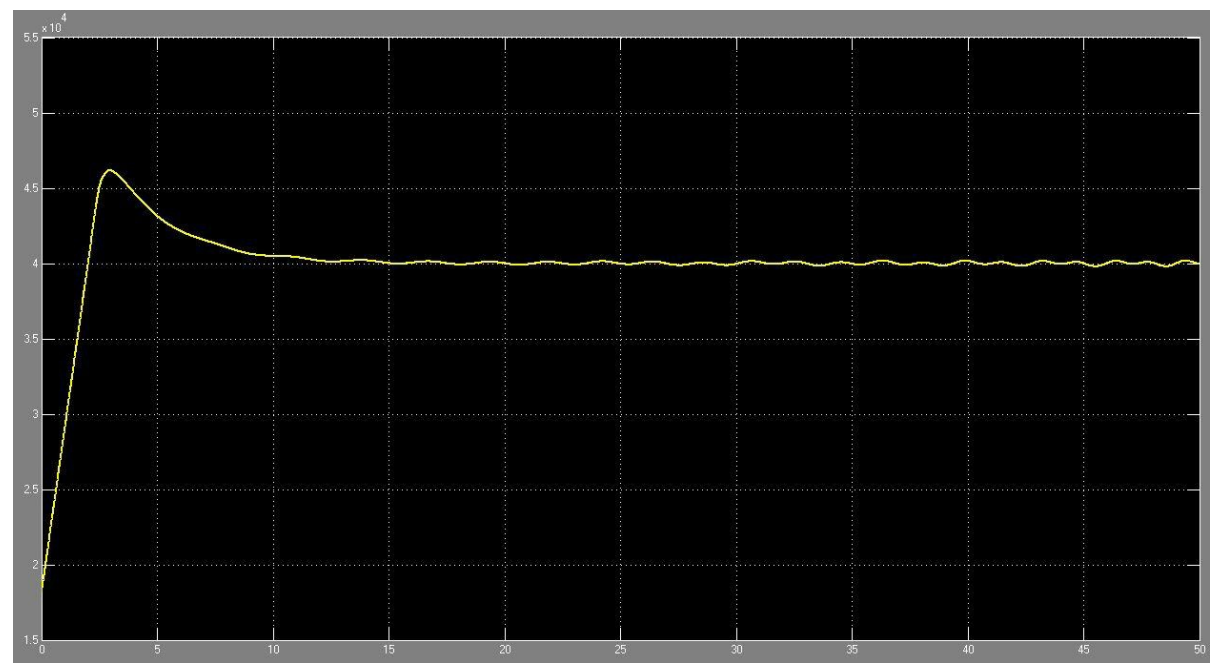

Fig. 8 Speed of compressor in scheme 4

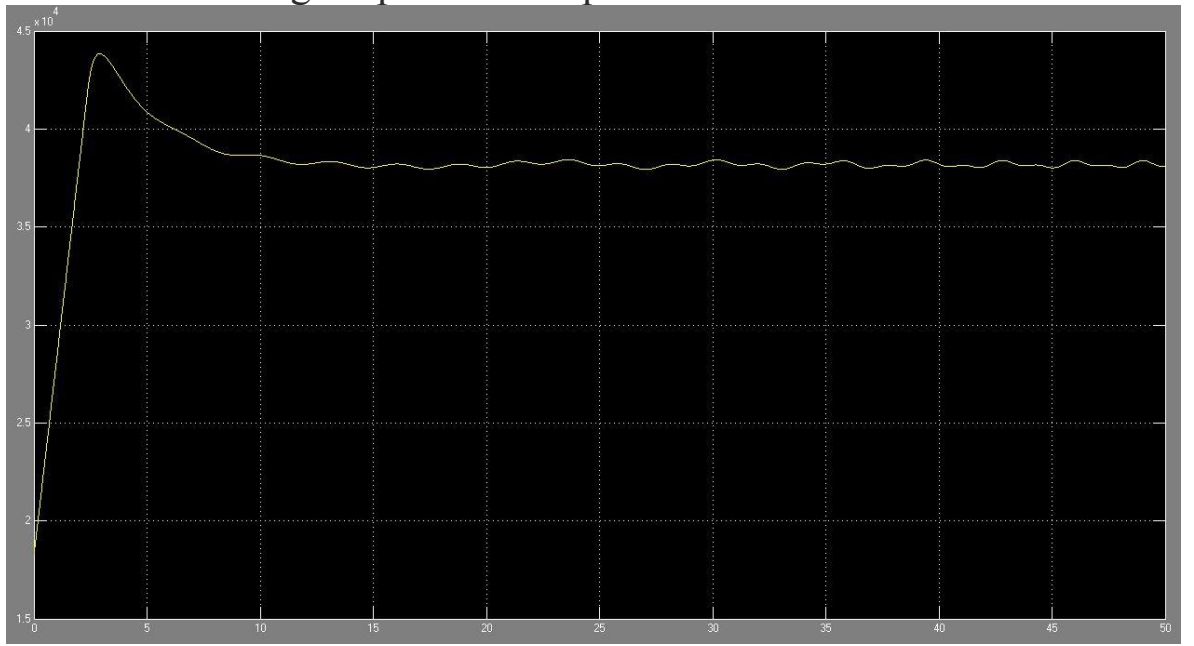

Fig.9 Speed of motor in scheme 4

It can be seen that the speed of compressor can eventually stabilize at about 40000rpm with a little oscillation amplitude up and down. But the speed of the motor is up to about 40000rpm which the actual motor can not reach without variable speed mechanism with higher transmission ratio. Variable speed mechanism may lead the system to be more complex.

In scheme 5 , the coefficient motor speed multiplied by is $Z_{7} /\left(Z_{1}+Z_{3}\right)$, the number turbine speed multiplied by is $\mathrm{Z}_{1} /\left(\mathrm{z}_{1}+\mathrm{z}_{3}\right)$. The result is shown in Fig.10 and Fig.11.

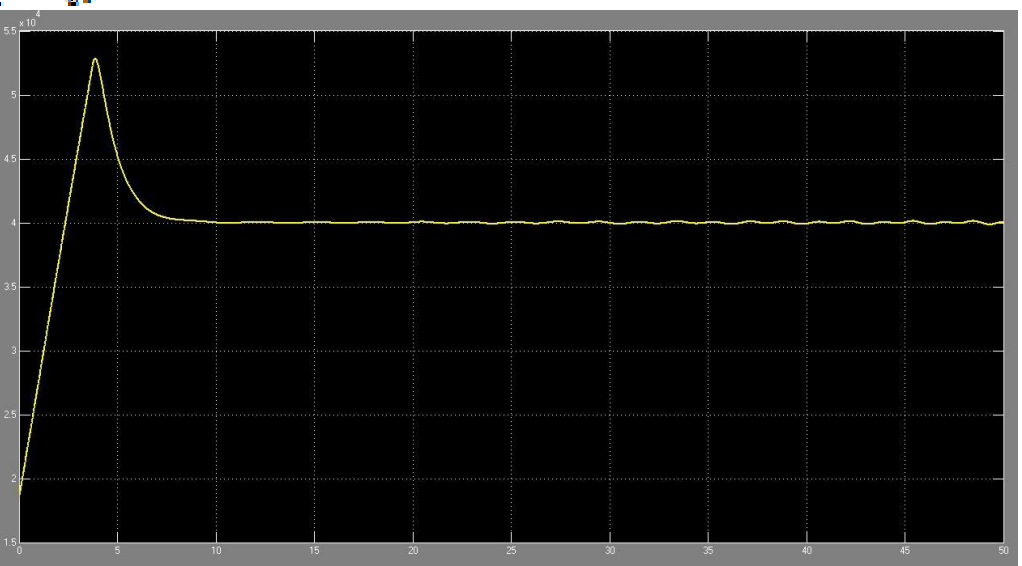

Fig.10 Speed of compressor in scheme 5 


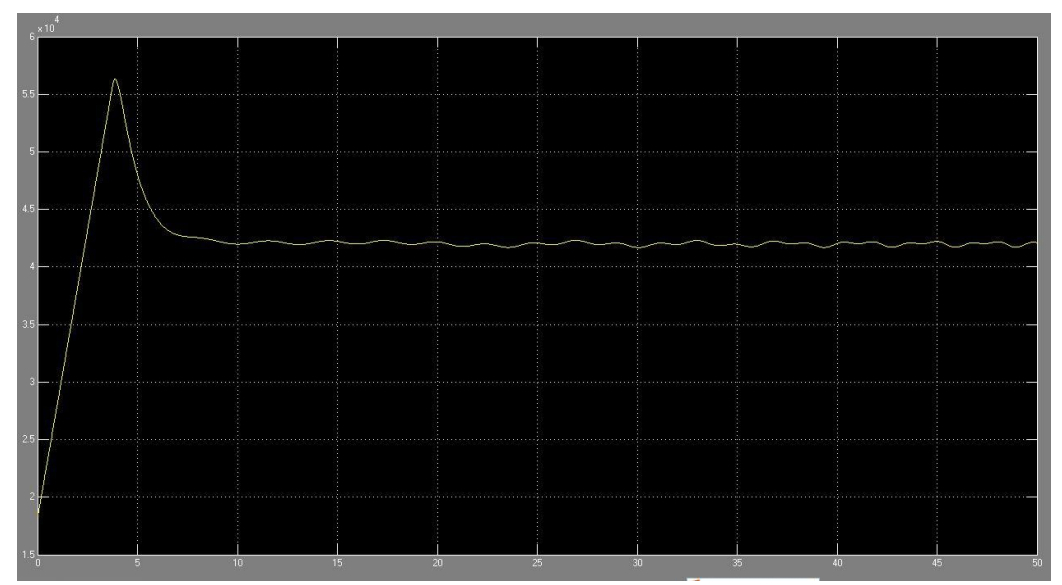

Fig.11 Speed of motor in scheme 5

Similar to the scheme 4, the speed of motor is higher than the actual condition, and even so is compressor speed. So it required additional variable speed device if it want to work normally.

In scheme 6 , the coefficient motor speed multiplied by is $\left(-\mathrm{Z}_{1 / 2}\right)$, the number turbine speed multiplied by is $\left(Z_{1}+Z_{2}\right) / Z_{3}$. The result is shown in Fig. 12 .

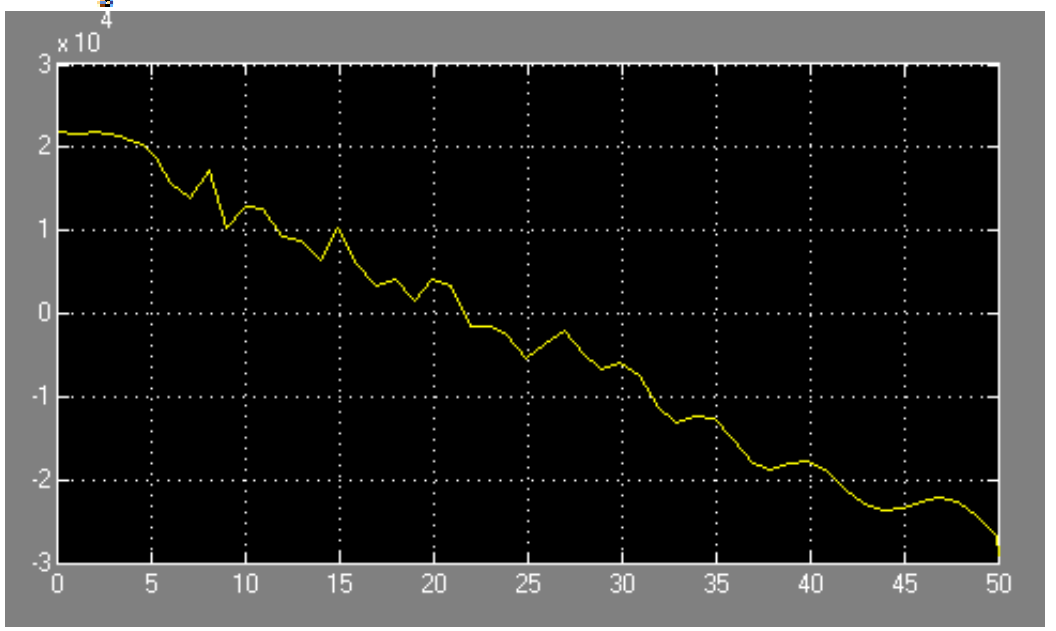

Fig.12 Speed of compressor in scheme 6

It can be seen that the speed of compressor can not be adjusted to the efficient speed.

\section{Conclusions}

A new kind of electronic auxiliary booster device driven by planet gear mechanism is designed in this paper. Specifically, it is to separate the turbine and compressor installed on the same shaft in traditional plan to be connected into a planetary gear train with a motor. motor speed and turbine speed work as the input into the planet gear mechanism, and the compressor speed as the output. The compressor can work as much as possible under the efficient speed through real-time adjustment of motor speed. As a result, the energy of exhaust can be better and more used. The model is built and simulated by Simulink in Matlab software under appropriate simplifying conditions. Results of all six schemes are shown through the simulation, and it is the scheme 1 that is the best after the comparison each other. This design has a significant scientific meaning and actual value.

\section{References}

[1] Boretti A. Improving the efficiency of turbocharged spark ignition engines for passenger cars through waste heat recovery[J]. Combustion, 2012, 2013: 10-10.

[2] Wang H, Wang H, Zhang Z. Optimization of low-temperature exhaust gas waste heat fueled organic Rankine cycle[J]. Journal of Iron and Steel Research, International, 2012, 19(6): 30-36 
[3] ZHANG X, Ke Z, Sujuan B A I, et al. Exhaust Recovery of Vehicle Gasoline Engine Based on Organic Rankine Cycle[R]. SAE Technical Paper, 2011.

[4] Zhuge W, Huang L, Wei W, et al. Optimization of an electric turbo compounding system for gasoline engine exhaustenergy recovery[J]. SAE paper, 2011: 01-0377

[5] Boretti A. Advances in Waste Heat Recovery Systems for Gas Engines[J]. Surface Engineering, 2011: 09-13.

[6] Ismail Y, Durrieu D, Menegazzi P, et al. Potential of Exhaust Heat Recovery by

Turbocompounding[J]. Diesel Engine, 2012, 2012: 12-04. 